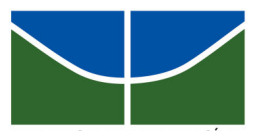

UNIVERSIDADE DE BRASÍLIA

Centro de Excelência em Turismo

Pós-graduação Lato Sensu

Curso de Especialização em Gastronomia e Saúde

\title{
O PROCESSO DE VINIFICAÇÃO E O CONTEÚDO DE ANTIOXIDANTES
}

Alicia Gomes Fernandes

Dra Sandra Fernandes Arruda

Brasília - 2008 


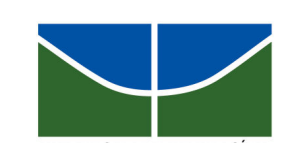

UNIVERSIDADE DE BRASÍLIA

Centro de Excelência em Turismo

Pós-graduação Lato Sensu

Curso de Especialização em Gastronomia e Saúde

\title{
O PROCESSO DE VINIFICAÇÃO E O CONTEÚDO DE ANTIOXIDANTES
}

\author{
Alicia Gomes Fernandes \\ Dra Sandra Fernandes Arruda \\ Monografia apresentada ao Centro de \\ Excelência em Turismo - CET, da \\ Universidade de Brasília - UnB, como \\ requisito parcial à obtenção do grau de \\ Especialista em Gastronomia e Saúde
}

Brasília - 2008 
UNIVERSIDADE DE BRASÍLIA

Centro de Excelência em Turismo

Pós-graduação Lato Sensu

Curso de Especialização em Gastronomia e Saúde

Alicia Gomes Fernandes

Aprovado por:

Professora Dra. Sandra Fernandes Arruda

Professora Dra. Wilma Maria Coelho Araújo

Professora MSc. Lívia de Lacerda de Oliveira Pinelli

Brasília, 22 de julho de 2008. 
DEDICATÓRIA

Para minha mãe: exemplo, força e amor.

Te amo! 


\section{AGRADECIMENTOS:}

A Professora Dra Sandra Fernandes Arruda, pela atenção, orientação e correção deste trabalho;

A Força Aérea Brasileira, pelo investimento no Curso de Gastronomia e Saúde;

Ao Brig Paulo de Moura Moutella pelo incentivo na busca de conhecimentos sobre Gastronomia;

Ao Professor Hugo Caracas pelas instruções no EndNote e...

A Deus... porque sem Ele, nada acontece! 


\section{LISTA DE FIGURAS}

Figura 1 Principais classes de compostos fenólicos encontrados no vinho 14

Figura 2 Relação entre o tempo de maceração e o ITP em vinhos tintos 20 


\section{LISTA DE TABELAS}

Tabela 1 Concentração (C) de Polifenóis Totais expressa em mg de Ácido Gálico (AG) em produtos brasileiros derivados da uva

Tabela 2 Conteúdo de fenólicos, em mg ácido gálico / L em bebidas consideradas fontes de polifenóis

Tabela 3 Índice de Polifenóis Totais em Vinhos Tintos e Brancos

Tabela 4 Consumo de vinho em litros per capita em alguns países no ano de 2005

Tabela 5 Concentração de antioxidantes em vinhos brasileiros e de outros países 


\section{Resumo}

O vinho é considerado uma boa fonte de antioxidantes da dieta. O consumo moderado de vinho é associado a prevenção da aterosclerose, doença coronariana isquêmica, ,câncer e a efeitos anti-inflamatórios e anti-trombogênicos. Os diferentes tipos de vinhos, tintos, roses e brancos apresentam variada composição de compostos fenólicos. O conteúdo de antioxidantes do vinho depende não apenas da variedade da uva como de outros fatores como as técnicas de vinificação utilizadas na fabricação do vinho tais como: tempo de maceração, temperatura, contato do mosto com a parte sólida, cascas e engaços, exposição ao oxigênio, entre outros.

Palavras-chave: vinho, vinificação, conteúdo de fenóis, maceração carbônica, termovinificação, enologia 


\begin{abstract}
Wine is considered a good source of dietary antioxidants. Moderate wine consumption has been associated with protection against the development of atherosclerosis, coronary heart disease, cancer and it is also associated with an anti-inflamatory and anti-trombotic effects. Although red, rosès and white wines have different phenolic composition, the antioxidant content does not depends only on the grape variety but also is influenced by enologycal practices such as maceration time, temperature, stem, seeds and pomace contact oxygen exposition and others.
\end{abstract}

Keywords: wine, vinification, phenolic content, carbonic maceration, thermovinification, enology 


\section{SUMÁRIO}

1. Introdução. 11

2. Compostos Antioxidantes presentes no Vinho: estrutura química e classificação. 12

3. Visão Geral do Processo de Vinificação. 15

4. Características que diferenciam os vinhos branco e tinto. 17

5. O Processo Produção de Vinhos e suas Variações e Conseqüentes diferenças na Composição 18 do Produto.

6. O processo de envelhecimento do vinho 21

7. O vinho e sua importância funcional. 21

8. Conclusão. 22

9. Referências Bibliográficas. 25 


\section{INTRODUÇÃO:}

$\mathrm{Na}$ idade antiga, a transformação da uva em vinho, processo denominado vinificação, era considerada apenas uma arte. Atualmente, com o crescimento da preocupação com a saúde dos indivíduos, o padrão de qualidade do vinho passa a considerar tanto a qualidade sensorial quanto o valor funcional que este apresenta (KING et al., 2005).

No estudo denominado MONICA (Estudo Multinacional de Tendências e Determinantes de Doença Cardiovascular) foi observado que, apesar do elevado consumo de gorduras saturadas; prevalência de fumantes similar a outros países, elevada prevalência de níveis de colesterol acima do normal e pressão arterial elevada, a incidência de doença cardiovascular era menor do que em outros países. Este fato foi atribuído ao alto consumo de álcool e de antioxidantes por humanos, ambos encontrados no vinho (BURR, 1995).

Um estudo realizado na cidade de Copenhague com 13.000 indivíduos mostrou correlação inversa entre o consumo de álcool e o risco de doença coronariana, mas esta relação era aplicada somente para indivíduos que consumiam vinho. Cerveja e outras bebidas alcoólicas não teriam o mesmo efeito. .(GRONBAEK et al., 2000).

A ingestão moderada, isto é de 1 a 2 taças de vinho tinto por dia traz benefícios a saúde (WOLLIN et al., 2001). A Associação Americana do Coração (American Heart Association) define como moderada a ingestão de 1 dose por dia para mulheres e até duas doses por dia para homens (ELLISON, 2001), pois o consumo excessivo de álcool pode causar intoxicação, vício, cirrose hepática e diversos tipos de câncer como de boca, esôfago e fígado (BERTELLI, 2007).

O consumo de bebidas alcoólicas não é uma recomendação universal. Crianças, gestantes, lactantes (GIGLIA et al., 2008), doentes hepáticos (ZAKHARI et al., 2007), pacientes com hiperuricemia, cardiomiopatia alcoólica e em uso de medicamentos que possuam alguma interação com o álcool, como ansiolíticos e anti-epiléticos, entre outros, não devem ingerir vinho (Opie 2007). Para estes indivíduos ou outros abstêmios é recomendado o consumo de sucos de uva integral ou reprocessado, que possuem 
concentração de polifenóis totais que se aproximam do vinho tinto (SAUTTER et al., 2005), como mostra a tabela 1 .

Tabela 1: Concentração (C) de Polifenóis Totais expressa em mg de Ácido Gálico (AG) em produtos brasileiros derivados da uva.

\begin{tabular}{|l|c|c|l|}
\hline Produto & $\begin{array}{c}\text { C mínima } \\
\mathrm{mg} / \mathrm{L}\end{array}$ & $\begin{array}{c}\text { C máxima } \\
\mathrm{mg} / \mathrm{L}\end{array}$ & Autor \\
\hline Suco Integral & 1617,4 & 2213,2 & (SAUTTER et al., 2005) \\
\hline Vinho Merlot & 430,3 & 1992,6 & (FREITAS, 2000) \\
\hline Vinho Carbernet Sauvignon & 491,4 & 1722,3 & (FREITAS, 2000) \\
\hline Vinho Tannat & 491,4 & 1722,3 & (FREITAS, 2000) \\
\hline Suco Reprocessado & 1551,7 & 1615,9 & (SAUTTER et al., 2005) \\
\hline $\begin{array}{l}\text { Suco reconstituído } \\
\text { adoçado }\end{array}$ & 205,4 & 933,4 & (SAUTTER et al., 2005) \\
\hline
\end{tabular}

Os vinhos tintos, rosès e brancos apresentam diferente composição e concentração de compostos fenólicos. A maior concentração é usualmente encontrada em vinhos tintos, pois durante o processamento ocorre a fermentação das uvas ainda com casca, com o objetivo de extrair o pigmentos responsáveis pela cor do vinho (PIMENTEL et al., 2005). Contudo, o conteúdo de antioxidantes do vinho não depende somente da variedade da uva, existem outros fatores no processo de vinificação que atuam diretamente qualidade nutricional e sensorial do produto como tempo e modo de maceração, temperatura, contato do mosto com a casca, sementes e engaços, exposição ao oxigênio, entre outros (SUN

$$
\text { et }
$$$$
\text { al., }
$$

2001).

\section{Compostos Antioxidantes presentes no Vinho: estrutura}

\section{química e classificação}

Muitas reações metabólicas produzem Espécies Reativas de Oxigênio (ERO). As ERO são moléculas muito reativas e instáveis produzidas pela quebra de ligações covalentes ou abstração de elétrons não ligados freqüentemente na presença de íons 
metálicos oxidados. A instabilidade destas moléculas é devida a presença de um ou mais elétrons não pareados (WATERHOUSE, A. L.; et al., 2006)

As ERO podem provocar danos às proteínas, lipídeos e ao DNA. Estes danos são inibidos ou reparados pelas defesas antioxidantes do organismo. Alguns fatores exógenos como a fumaça do tabaco, radiações ionizantes, solventes orgânicos e pesticidas podem potencializar a produção de ERO superando a capacidade antioxidante do organismo, estabelecendo-se a condição denominada estresse oxidativo. A ingestão de antioxidantes através da dieta auxilia o organismo a neutralizar as ERO, restaurando o equilíbrio e evitando o estresse oxidativo. Estes podem agir inibindo enzimas oxidantes ou sendo cofatores de enzimas anti-antioxidantes (RAMOS et al., 2000; YILDIRIM et al., 2001) .

O vinho é considerado uma boa fonte de antioxidantes da dieta, comparado a outras bebidas, como mostra a tabela 2, sendo capaz de prevenir doenças como o câncer, doença coronariana, doenças amilodoigênicas (PIGNATELLI et al., 2006; GAMBUTI et al., 2007).

Tabela 2: Conteúdo de fenólicos, em mg ácido gálico / L em bebidas consideradas fontes de polifenóis

\begin{tabular}{|l|c|}
\hline Bebida & $A G(\mathrm{mg} / \mathrm{L})$ \\
\hline Suco de romã & 3.800 \\
\hline Vinho tinto & 3.500 \\
\hline Suco de uva & 2.600 \\
\hline Suco de jabuticaba & 2.300 \\
\hline Suco de cereja negra & 2.100 \\
\hline Suco de açá & 2.100 \\
\hline Suco de cranberry & 1.700 \\
\hline Chá branco gelado & 900 \\
\hline Chá verde gelado & 800 \\
\hline Suco de laranja & 700 \\
\hline Chá preto gelado & 400 \\
\hline Suco de maçã & 400 \\
\hline
\end{tabular}

$\mathrm{AG}=$ ácido gálico

Adaptado de (SEERAM et al., 2008)

Entre os diversos compostos antioxidantes presentes na dieta e especialmente nos vinhos estão os flavonóides. Esta família de compostos é capaz de inibir a oxidação de lipídios ou outras moléculas, evitando o início ou propagação das reações de oxidação em cadeia. A atividade antioxidante de compostos fenólicos é atribuída principalmente às 
suas propriedades de óxido-redução, sendo capazes de neutralizar os radicais livres, seja através da captação da energia extra do oxigênio triplete e singlete ou decompondo peróxidos, relacionados a doenças coronarianas, câncer, envelhecimento, aterosclerose, entre outras (BRENNA et al., 2001).

Os flavonóides são substâncias polifenólicas de baixo peso molecular encontradas em frutas como morango, cereja, romã, uva, amora, laranja, açaí, maçã, em bebidas como chá preto e chá verde, entre outros (SEERAM et al., 2008). Sua estrutura é baseada em um núcleo polifenol, que consiste em 3 anéis fenólicos indicados como $\mathrm{A}, \mathrm{B}$ e $\mathrm{C}$, nas estruturas representadas na figura 1. O benzeno do primeiro anel é condensado com o sexto carbono do terceiro anel que na posição 2 carrega um anel de fenil-benzeno como substituinte. O terceiro anel pode ser um pirano heterocíclico, gerando as estruturas básicas das leucoantocianinas (ou proantocianinas ou catequinas) e as antocianidinas, denominado de núcleo flavona. No caso do terceiro anel apresentar como uma pirona ocorre a formação das flavonas, flavonóis, flavanonas, isoflavonas, chalconas e auronas, recebendo a denominação de núcleo 4-oxo-flavonóide. Na figura 1, estão representadas as estruturas das principais classes de flavonóides encontradas no vinho (AHERNE et al., 2002).

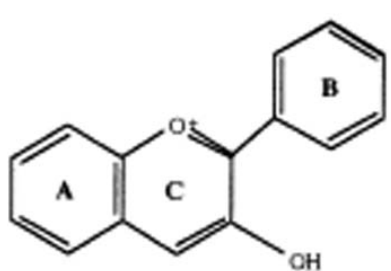

Antocianidinas

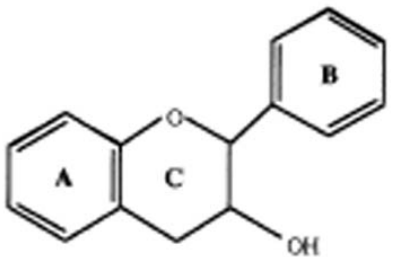

Catequinas<smiles>O=c1c(O)c(-c2ccccc2)oc2ccccc12</smiles>

Flavonóides

Figura 1. Principais classes de compostos fenólicos encontrados no vinho 
A atividade antioxidante de compostos fenólicos deve-se principalmente à propriedade redutora de sua estrutura química. Em função dessa propriedade essas moléculas desempenham um papel importante na neutralização de ERO e quelação de metais de transição, agindo tanto na etapa de iniciação como na propagação do processo oxidativo. Os intermediários formados pela ação de antioxidantes fenólicos são relativamente estáveis, devido à ressonância do anel aromático presente na estrutura destas substâncias (SOUSA et al., 2007).

O resveratrol é um polifenol da família das viniferrinas que tem poder antioxidante, sendo capaz de inibir a oxidação de lipoproteínas de baixa densidade (LDL), inibir a produção de eicosanóides, agregação plaquetária e quimioprevenção do câncer (IGNATOWICZ et al., 2001).

Compostos como as antocianinas, taninos, catequinas, quercetinas e epicatequinas parecem também serem responsáveis pelos efeitos benéficos à saúde atribuídos ao vinho (GAMBUTI et al., 2007).

As antocianinas são os pigmentos que dão cor vermelha, azul ou roxa às frutas, folhas e outros tecidos vegetais, pertencentes a classe dos flavonóides que demonstram ter atividade biológica antioxidante, antiinflamatória, antimicrobianas e anticarcinogênicas (MAZZA, 2007). A quercetina também possui ação antioxidante, antiinflamatória e atenuante de processos alérgicos (SHAIK et al., 2006).

\section{Visão Geral do Processo de Vinificação}

O processo de vinificação começa com a avaliação das condições sanitária e de maturação da uva após a colheita. Segue-se então o processo de esmagamento e desengaçamento. No esmagamento os bagos passam por uma prensa de borracha para romper sua casca e liberar o suco. $\mathrm{O}$ desengaçamento consiste no processo de separação dos bagos e engaços, partes lenhosas do cacho que prendem os bagos (SANTOS, 2006).

O processo de esmagamento pode ser substituído pela maceração carbônica onde, ao invés de uma prensa, é injetado gás carbônico em um tanque hermeticamente fechado. Em condições anaeróbias, a baga sofre fermentação intracelular, em que o açúcar é transformado em álcool etílico e em outras substâncias (BERTAGNOLLI et al., 2007). 
Este processo é recomendável quando se dispõe de uvas inteiras, baixo teor de tanino e elevada concentração de ácido málico, açúcar e antocianinas. Nesta fase, os constituintes da parte sólida da uva passam para a parte líquida do mosto através dos fenômenos de dissolução e difusão (RIZZON et al., 1999).

Após esta etapa é realizada a sulfitagem, processo que consiste na adição de dióxido de enxofre gasoso, com solução aquosa de dióxido de enxofre, ou bissulfito de potássio, com sulfito de amônio. Este processo tem como objetivo ativar a fermentação alcoólica, bloquear a ação de bactérias e impedir a oxidação do mosto (CURVELOGARCIA, 2005).

O próximo passo é a adição de leveduras da cepa Saccaromyces cerevisae, caso necessário. A temperatura do mosto aumenta, pois a fermentação é um processo exotérmico, e há produção de gás carbônico, que vai para a parte superior do tanque formando com as cascas, uma parte sólida denominada chapéu. O liquido próximo ao chapéu adquire cor, devido ao contato com as cascas.

O processo chamado de remontagem, rotação do mosto claro do fundo com o mosto próximo ao chapéu, permite a uniformização da cor.

Após este processo é feita a descuba: separação da parte sólida da líquida. A parte líquida é transferida para o tanque de fermentação malolática, processo no qual o ácido málico é transformado em ácido lático com o objetivo de diminuir a acidez total. Logo após, a parte líquida é submetida a nova decantação (RIZZON et al., 2006). A parte sólida do mosto pode ser utilizada na fabricação de extratos com finalidades terapêuticas (DE CAMPOS et al., 2008).

Após a descuba é realizada nova sulfitagem e o vinho passa então para o processo de envelhecimento, quando o produto desejado é um vinho envelhecido.

Os vinhos varietal, de um único tipo de uva, sofrem diretamente o engarrafamento. Em vinhos não varietais, é realizado o corte, que consiste na mistura de vinhos feitos de diferentes tipos de uva, de modo a otimizar o produto final. No processo de fabricação de vinhos brancos antes da fermentação, pode ser aplicado processo de chaptalização, que consiste na adição de açúcar ao mosto para que o vinho atinja o conteúdo alcoólico necessário a sua conservação. Na fabricação de vinhos brancos o 
mosto não é fermentado com as cascas, não adquirindo cor (RIZZON et al., 2006; SANTOS, 2006).

\section{Características que diferenciam os vinhos branco e tinto}

Os vinhos tintos possuem maior concentração de antioxidantes que os vinhos brancos devido ao processo de fermentação do mosto, que ocorre em contato com as cascas, liberando principalmente as antocianinas (LAMUELA-RAVENTOS et al., 1999; KATALINIC et al., 2004; PIGNATELLI et al., 2006). Porém alguns pesquisadores já desenvolveram tecnologias para produzir vinhos brancos com maior quantidade de antioxidantes, utilizando álcool etílico na extração de polifenóis da casca de uvas verdes (FUHRMAN et al., 2001).

A tabela 3 mostra o índice de polifenóis totais (IPT) de vinhos varietais de diversas uvas na produção de vinhos brancos e tintos. 
Tabela 3: Índice de Polifenóis Totais em Vinhos Tintos e Brancos

\begin{tabular}{|l|c|l|}
\hline Tipo de uva/vinho & IPT (I 280) & Autor \\
\hline Isabel/ Tinto & $24,3 \pm 6,2$ & (RIZZON et al., 2000) \\
\hline Cabernet Franc / Tinto & $25,3 \pm 6,6$ & (RIZZON et al., 2001) \\
\hline Merlot / Tinto & $31,3 \pm 4,1$ & (RIZZON et al., 2003) \\
\hline Cabernet Sauvignon/ Tinto & $31,8 \pm 6,1$ & (RIZZON et al., 2002) \\
\hline Tannat / Tinto & $43,0 \pm 12,7$ & (RIZZON et al., 2004) \\
\hline Tinto R9 & 34,25 & (ALONSO et al., 2002) \\
Tinto R1 & 33,40 & \\
Tinto R3 & 31,75 & \\
Tinto R7 & 30,35 & \\
Tinto R5 & 30,30 & \\
Tinto R11 & 26,10 & \\
Tinto R6 & 24,85 & \\
Tinto R4 & 24,28 & \\
Tinto R10 & 24,20 & \\
Branco W1 & 17,43 & \\
Branco W2 & 12,86 & \\
Branco W3 & 10,66 & \\
Branco W4 & 7,03 & \\
\hline
\end{tabular}

R9, R1, R3, R7, R5, R11, R6, R4, R10 - Amostras de vinho tinto / W1, W2, W3 e W4 - amostras de vinho branco. I 280: índice de polifenóis a $280 \mathrm{~nm}$.

Apesar da menor concentração dos antioxidantes, estudos in vivo mostram que o vinho branco também pode atuar na prevenção de doenças cardiovasculares, quando consumido em quantidade moderada (LAMUELA-RAVENTOS et al., 1999; RAJDL et al., 2007).

\section{O Processo Produção de Vinhos e suas Variações e} Conseqüentes diferenças na Composição do Produto

A literatura mostra que os vinhos produzidos a partir da fermentação da casca em contato com o engaço, possuem maior concentração de polifenóis, especialmente 
catequinas, comparados àqueles produzidos com a retirada dos engaços. O contato prolongado do mosto-vinho com a casca favorece a liberação principalmente de catequinas e proantocianinas presentes nesta parte da uva e responsáveis pela coloração do produto (SUN et al., 2001).

Proteger o mosto do oxigênio e da luz, durante as mudanças de tanque também é um cuidado importante para obtenção de um produto com maior conteúdo de antioxidantes, pois estes fatores promovem a oxidação de compostos presentes nas uvas (WATERHOUSE, A. L. et al., 2006). A utilização da maceração carbônica em substituição ao esmagamento convencional é a mais indicada para obter este resultado devido às condições anaeróbias do processo. $\mathrm{O}$ uso de fermentadores rotatórios podem diminuir a quantidade total de antocianinas devido o aumento da aeração do vinho (SUN et al., 2001).

A elevação da temperatura de maceração aumenta a permeabilidade das paredes celulares das uvas, resultando no aumento expressivo do conteúdo de compostos fenólicos (ZIMMAN et al., 2002).

A técnica de flash release (FR) consiste no aquecimento rápido das uvas, atingindo temperatura maior que $95^{\circ} \mathrm{C}$ em pressão atmosférica. Após o aquecimento, as uvas são submetidas a um forte vácuo que promove vaporização instantânea da água presente na fruta, causando fragilização das paredes celulares e a inativação da polifenoloxidase, enzima responsável pela oxidação dos polifenóis. Os polifenóis são liberados mais rapidamente e em maior quantidade. Em estudo comparando a concentração de flavonóides no mosto obtido pelo método tradicional e FR, os resultados mostraram que: a concentração de antocianinas no mosto controle de uva Carignan era de $0,0 \mathrm{mg} / \mathrm{L}$ e no mosto da mesma uva produzido por FR foi de $351,1 \pm 24,2 \mathrm{mg} / \mathrm{L}$. No mosto da variedade Mourvedre, a concentração de flavonóides variou de $0 \mathrm{mg} / \mathrm{L}$ no mosto padrão para $57,7 \pm 0,8 \mathrm{mg} / \mathrm{L}$ no produzido por FR. Esta técnica também é recomendada na fabricação de vinhos a partir de uvas cuja qualidade sanitária é deficiente (MOREL-SALMI et al., 2006).

De forma geral, no processo de maceração, o fator determinante do conteúdo de antioxidantes é o tempo em que o mosto fica em contato com sua parte sólida. Quanto maior o tempo, maior a liberação de antioxidantes pelas cascas e pelas sementes da uva 
(SUN et al., 2001; ZIMMAN et al., 2002; MOREL-SALMI et al., 2006). Villaño et al (2006) acompanharam o ínidice total de polifenóis expresso em $\mathrm{mmol} / \mathrm{L}$ de equivalente de ácido gálico (EAG) em vinhos das varietais Syrah, Tempranillo e Carbernet Sauvignon durante 14 dias, encontrando relação direta entre o tempo de maceração e o conteúdo de polifenóis, como mostra a figura 2.

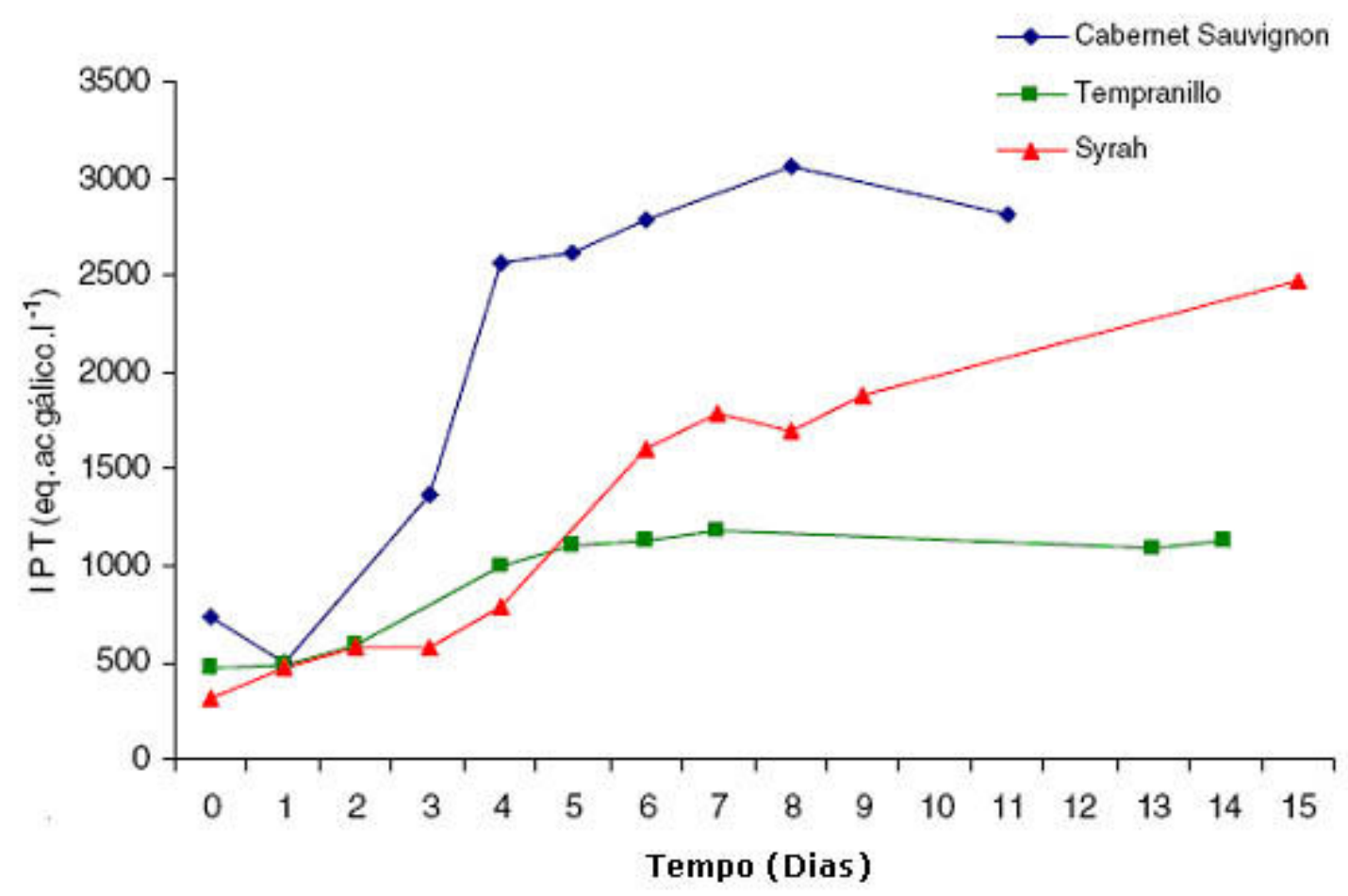

Fig 2. Relação entre o tempo de maceração e o ITP em vinhos tintos.

(VILLAÑO et al., 2006)

Em trabalho realizado com uvas Merlot e Cabernet Sauvignon, ambos fermentados em diferentes tanques, apresentaram conteúdo de polifenóis totais (PT) crescente do $1^{\circ}$ ao $8^{\circ}$ dia, chegando a variar de $3,4 \pm 0,1 \mathrm{mmol} / \mathrm{L}$ GAE no suco para $8,8 \pm$ $0,1 \mathrm{mmol} / \mathrm{L}$ GAE no $3^{\circ}$ dia de fermentação, até $11,4 \pm 0,1 \mathrm{mmol} / \mathrm{L}$ GAE no $8^{\circ}$ dia do processo (BURNS et al., 2001) 


\section{O processo de envelhecimento do vinho}

Durante o envelhecimento dos vinhos em barris, a madeira porosa permite a entrada de pequenas quantidades de oxigênio que promovem a conversão do etanol em etanal. Este, por sua vez, reage com os polifenóis, formando compostos importantes para as qualidades sensoriais do vinho. Devido ao alto custo dos barris de carvalho, algumas vinícolas utilizam a técnica de micro-oxigenação, injeção de pequenas quantidades de oxigênio no vinho. $\mathrm{O}$ envelhecimento em barris ou em tanques de aço com microoxigenação tem o objetivo de diminuir a adstringência e o sabor herbáceo do produto final. A presença de oxigênio em pequenas quantidades favorece a combinação de antocianinas e flavonóides através de pontes etil, produzindo polímeros de polifenol, que também possuem capacidade de estabilizar radicais livres durante o processo de envelhecimento da bebiba (LLAUDY MDEL et al., 2006). Rossetto \& Vanzani (2004) demonstraram que o processo de envelhecimento de vinhos tintos italianos por 7 anos, aumentou a concentração de polímeros de polifenol e diminui a concentração de antocianinas livres, que pode ser explicado pela ligação destas com fenóis (ROSSETTO et al., 2004).

Pellegrini et al. (2000) relacionam a diminuição da capacidade antioxidante dos vinhos envelhecidos à diminuição da biodisponibilidade dos fenóis pois, durante o envelhecimento estes se polimerizam, não sendo absorvidos no intestino humano. Sendo assim, pode-se considerar que os vinhos jovens são melhores fontes de antioxidantes, devido a maior biodisponibilidade destes no produto final (PELLEGRINI et al., 2000).

\section{O vinho e sua importância funcional}

As complicações da aterosclerose representam as maiores causas de morbidade e mortalidade no mundo. Alguns estudos já citados propõem que o consumo moderado de bebidas alcoólicas pode estar relacionado com a diminuição do risco de aterosclerose, embora não exista um consenso de qual seria a dose exata recomendada para usufruir de tais benefícios. Os mecanismos pelos quais o álcool atuaria também não são explicados (RAJDL et al., 2007). 
Dentre as bebidas alcoólicas, o vinho tem sido recomendado como fonte de antioxidantes da dieta, como forma de auxiliar na prevenção da aterosclerose aumentando os níveis de HDL e apolipoproteína A (RAJDL et al., 2007), e diminuindo os níveis de LDL plasmáticos (VITRAC et al., 2005).

O consumo de vinho também é relacionado com a diminuição da pressão arterial sistêmica, pois promove relaxamento do endotélio, modulação da liberação de interleucina-6 no plasma (WILLIAMS et al., 2004) e melhora da função plaquetária (KIKURA et al., 2004), através da inibição das prostraglandinas na agregação plaquetária (WU et al., 2007).

Os antioxidantes encontrados no vinho também atuam neutralizando ERO que podem causar alterações em diversas moléculas, inclusive do DNA (RUDOLF et al., 2007).

O resveratrol, um dos principais antioxidantes do vinho tinto, é considerado cardio e quimioprotetor. Alguns trabalhos sugerem uma atividade neuroprotetora do resveratrol, exercida através da redução da proteína beta-amilase em estudos realizados com cultura de células (SAVASKAN et al., 2003; MARAMBAUD et al., 2005)

\section{Panorama Brasileiro da Produção e Consumo de Vinho}

O Brasil tem apresentado uma crescente produção de uvas, concentrando-se principalmente no Rio Grande do Sul, região responsável por $90 \%$ da produção vinícola nacional. Nos últimos anos, o consumo de vinhos pela população brasileira apresentou tendência de crescimento. Se considerarmos o consumo interno de vinhos finos (nacionais e importados), houve crescimento de 13,02\%, passando de 71,46 milhões de litros em 2006 para 80,76 milhões de litros em 2007 (MELLO, 2007).

Os últimos dados da Organização Internacional da Vinha e do Vinho (OIV), mostram que houve um crescimento de 49,8\% na produção de vinhos no Brasil de 2003 para 2004, enquanto a produção mundial cresceu apenas 12,6\% no mesmo período (OIV, 2004). Apesar do grande aumento na produção, o consumo de vinho no Brasil ainda é considerado baixo - 1,65 L/ano per capita (WINE_INSTITUTE, 2005), como mostra a tabela 4. 
Tabela 4: Consumo de vinho em litros per capita em alguns países no ano de 2005

\begin{tabular}{|l|c|}
\hline País & Consumo \\
\hline França & 55,85 \\
\hline Itália & 48,16 \\
\hline Portugal & 46,67 \\
\hline Espanha & 34,66 \\
\hline Argentina & 28,81 \\
\hline Austrália & 24,67 \\
\hline Alemanha & 24,51 \\
\hline Chile & 15,5 \\
\hline Estados Unidos & 8,69 \\
\hline Japão & 1,96 \\
\hline Brasil & 1,65 \\
\hline Venezuela & 0,61 \\
\hline Moçambique & 0,42 \\
\hline Korea do Norte & 0,01 \\
\hline
\end{tabular}

Wine Institute, 2005.

A produção de vinhos tintos no Brasil é voltada para a produção de vinhos jovens, utilizando a termovinificação e a maceração carbônica, produzindo vinhos com características sensoriais diferenciadas do processo clássico e com conteúdo elevado de antioxidantes (RIZZON et al., 1999). A tabela 5 compara a concentração de antioxidantes em vinhos brasileiros e de outros países. 
Tabela 5: Concentração de antioxidantes em vinhos brasileiros e de outros países

\begin{tabular}{|l|c|c|c|}
\hline Autor & País & Varietal & C Média de PT (mg AG/L) \\
\hline $\begin{array}{l}\text { (PELLEGRINI } \text { et } 2000) \\
\text { (DÓKA } \text { et al., } \\
\text { 2002) }\end{array}$ & Itália & $\begin{array}{c}\text { Diversas - tintos jovens } \\
\text { Diversas - tintos } \\
\text { envelhecidos }\end{array}$ & $1605 \pm 337,4$ \\
\hline $\begin{array}{l}\text { (PAIXÃO } \text { et al., } \\
\text { 2007) }\end{array}$ & Portugal & Diversos - tintos & 1630 \\
\hline (KALLITHRAKA & Grécia & Diversos - tintos & 1871 \\
et al., 2006) & & & 2101,7 \\
\hline (VILLAÑO et al., & Espanha & Cabernet Sauvignon & 1137 \\
2006) & & Tempranillo & 2472 \\
\hline (FREITAS, 2000) & Brasil & Syrah & 1992,6 \\
\hline (BLASI, 2004) & Brasil & Mários tintos & 2134,76 \\
\hline
\end{tabular}

$\mathrm{C}=$ Concentração; $\mathrm{PT}=$ Polifenóis totais; $\mathrm{AG}=$ ácido gálico 


\section{Conclusão}

A crescente busca pela prevenção de doenças e a longevidade com qualidade de vida faz a população procurar cada vez mais por alimentos que tragam algum benefício à saúde. Em países como França, Itália e Estados Unidos de 1970 até 1999 o consumo de vinho per capita praticamente dobrou. Algumas regiões vinícolas tradicionais já utilizam como marketing o conteúdo de antioxidantes de seu produto (BISSON et al., 2002). No tocante às técnicas de fabricação, os vinhos tintos possuem mais antioxidantes que os brancos e quanto maior o tempo de contato do mosto com as cascas, mais antioxidantes são liberados no produto final. A proteção do vinho do oxigênio faz com que o mesmo não perca sua qualidade sensorial e conteúdo de antioxidantes. Os vinhos jovens possuem teor de antioxidantes biodisponíveis maior comparado aos envelhecidos. Como há uma ampla diversidade de técnicas de fabricação de vinhos, Waterhouse (2005) sugere que o conteúdo de antioxidantes venha expresso no rótulo do produto, em polifenóis totais, ou em subdivisões como antocianinas, ligninas e outros, afim de possibilitar o consumidor a escolha de um vinho pelo benefício que pode trazer à sua saúde (WATERHOUSE, 2005). Outro meio de possibilitar aos consumidores mais interessados conhecerem o conteúdo de antioxidantes, sem ônus na fabricação de rótulos, seria colocar estas informações disponíveis nos sítios das vinícolas na internet. O mesmo se aplica a sucos de uva integral, fontes de polifenóis para diversos grupos. O inquestionável é que, além do valor funcional do vinho, comparável a outras fontes, este possui o valor da tradição, do glamour e da harmonização de aromas e sabores que sempre fizeram da vinificação uma arte. 


\section{REFERÊNCIAS BIBLIOGRÁFICAS}

AHERNE, S. A.; O'BRIEN, N. M. Dietary flavonols: chemistry, food content, and metabolism. Nutrition, v.18, n.1, p.75-81. Jan 2002.

ALONSO, A. M.; DOMINGUEZ, C.; GUILLEN, D. A.; BARROSO, C. G. Determination of antioxidant power of red and white wines by a new electrochemical method and its correlation with polyphenolic content. J Agric Food Chem, v.50, n.11, p.3112-5. May 222002.

BERTAGNOLLI, S. M. M.; ROSSATO, S. B.; SILVA, V. L.; CERVO, T.; SAUTTER, C. K.; HECKTHEUER, L. H.; PENNA, N. G. Influência da maceração carbônica e da irradiação ultravioleta nos níveis de trans-resveratrol em vinhos de uva cabernet sauvignon. Revista Brasileira de Ciências Farmacêuticas, v.43, p.71-772007.

BERTELLI, A. A. Wine, research and cardiovascular disease: instructions for use. Atherosclerosis, v.195, n.2, p.242-7. Dec 2007.

BISSON, L. F.; WATERHOUSE, A. L.; EBELER, S. E.; WALKER, M. A.; LAPSLEY, J. T. The present and future of the international wine industry. Nature, v.418, n.6898, p.696-9. Aug 82002.

BLASI, T. C. Análise do Consumo e Constituintes Químicos de Vinhos produzidos na Quarta Colônia de Imigração Italiana do Rio Grande do Sul e Suas Relações Com as Frações Lipídicas Sanguíneas. 72 p.(Departamento de Ciência e Tecnologia de Alimentos, Universidade Federal de Santa Maria, Santa Maria - RS, 2004.

BRENNA, O. V.; PAGLIARINI, E. Multivariate Analysis of Antioxidant Power and Polyphenolic Composition in Red Wines. J. Agric. Food Chem., v.49, n.10, p.484148442001.

BURNS, J.; GARDNER, P. T.; MATTHEWS, D.; DUTHIE, G. G.; LEAN, M. E. J.; CROZIER, A. Extraction of Phenolics and Changes in Antioxidant Activity of Red Wines during Vinification. J. Agric. Food Chem., v.49, n.12, p.5797-58082001.

BURR, M. L. Explaining the French paradox. J R Soc Health, v.115, n.4, p.217-9. Aug 1995.

CURVELO-GARCIA, A. S. Práticas enológicas internacionalmente reconhecidas. Ciência Téc. Vitiv., v.20, n.2, p.105-1302005.

DE CAMPOS, L. M.; LEIMANN, F. V.; PEDROSA, R. C.; FERREIRA, S. R. Free radical scavenging of grape pomace extracts from Cabernet sauvingnon (Vitis vinifera). Bioresour Technol, v.99, n.17, p.8413-20. Nov 2008. 
DÓKA, O.; BICANIC, D. Determination of total polyphenolic content in red wines by means of the combined He-Ne laser optothermal window and Folin-Ciocalteu colorimetry assay. Anal. Chem., v.74, n.9, p.2157-2161. Mai 2002.

ELLISON, R. C. AHA Science Advisory on wine and health: A confusing message about alcohol consumption. Circulation, v.104, n.13, p.E72. Sep 252001.

FREITAS, D. M. Evolução dos parâmetros cromáticos e compostos fenólicos na conservação de vinhos tintos. 132 p.(Ciência e Tecnologia de Alimentos, Universidade Federal de Santa Maria, Santa Maria, 2000.

FUHRMAN, B.; VOLKOVA, N.; SURASKI, A.; AVIRAM, M. White wine with red wine-like properties: increased extraction of grape skin polyphenols improves the antioxidant capacity of the derived white wine. J Agric Food Chem, v.49, n.7, p.3164-8. Jul 2001.

GAMBUTI, A.; STROLLO, D.; ERBAGGIO, A.; LECCE, L.; MOIO, L. Effect of winemaking practices on color indexes and selected bioactive phenolics of Aglianico wine. J Food Sci, v.72, n.9, p.S623-8. Nov 2007.

GIGLIA, R. C.; BINNS, C. W.; ALFONSO, H. S.; SCOTT, J. A.; ODDY, W. H. The effect of alcohol intake on breastfeeding duration in Australian women. Acta Paediatr, v.97, n.5, p.624-9. May 2008.

GRONBAEK, M.; BECKER, U.; JOHANSEN, D.; GOTTSCHAU, A.; SCHNOHR, P.; HEIN, H. O.; JENSEN, G.; SORENSEN, T. I. Type of alcohol consumed and mortality from all causes, coronary heart disease, and cancer. Ann Intern Med, v.133, n.6, p.4119. Sep 192000.

IGNATOWICZ, E.; BAER-DUBOWSKA, W. Resveratrol, a natural chemopreventive agent against degenerative diseases. Pol J Pharmacol, v.53, n.6, p.557-69. Nov-Dec 2001 .

KALLITHRAKA, S.; TSOUTSOURAS, E.; TZOUROU, E.; LANARIDIS, P. Principal phenolic compounds in Greek red wines. Food Chemistry, v.99, p.784-7932006.

KATALINIC, V.; MILOS, M.; MODUN, D.; MUSIC, I.; BOBAN, M. Antioxidant effectiveness of selected wines in comparison with $(+)$-catechin. Food Chemistry, v.86, n.4, p.593-6002004.

KIKURA, M.; LEVY, J. H.; SAFON, R. A.; LEE, M. K.; SZLAM, F. The influence of red wine or white wine intake on platelet function and viscoelastic property of blood in volunteers. Platelets, v.15, n.1, p.37-41. Feb 2004. 
KING, R. E.; KENT, K. D.; BOMSER, J. A. Resveratrol reduces oxidation and proliferation of human retinal pigment epithelial cells via extracellular signal-regulated kinase inhibition. Chem Biol Interact, v.151, n.2, p.143-9. Jan 152005.

LAMUELA-RAVENTOS, R. M.; DE LA TORRE-BORONAT, M. C. Beneficial effects of white wines. Drugs Exp Clin Res, v.25, n.2-3, p.121-41999.

LLAUDY MDEL, C.; CANALS, R.; GONZALEZ-MANZANO, S.; CANALS, J. M.; SANTOS-BUELGA, C.; ZAMORA, F. Influence of micro-oxygenation treatment before oak aging on phenolic compounds composition, astringency, and color of red wine. $\mathbf{J}$ Agric Food Chem, v.54, n.12, p.4246-52. Jun 142006.

MARAMBAUD, P.; ZHAO, H.; DAVIES, P. Resveratrol Promotes Clearance of Alzheimer's Disease Amyloid-\{beta\} Peptides. J. Biol. Chem., v.280, n.45, p.3737737382. November 11, 20052005.

MAZZA, G. J. Anthocyanins and heart health. Ann Ist Super Sanita, v.43, n.4, p.369742007.

MELLO, L. M. R. Vitivinicultura Brasileira: Panorama 2007: Embrapa. 20082007.

MOREL-SALMI, C.; SOUQUET, J. M.; BES, M.; CHEYNIER, V. Effect of flash release treatment on phenolic extraction and wine composition. J Agric Food Chem, v.54, n.12, p.4270-6. Jun 142006.

OIV. Situation Report for the World Vitinicultural Sector in 2004. Organisation Internationale de la Vigne e du Vin, p.26-161. 2004

PAIXÃO, N.; PERESTRELO, R.; MARQUES, J. C.; CÂMARA, J. S. Relationship between antioxidant capacity and total phenolic content of red, rosè and white wines. Food Chemistry, v.105, p. 204-2142007.

PELLEGRINI, N.; SIMONETTI, P.; GARDANA, C.; BRENNA, O.; BRIGHENTI, F.; PIETTA, P. Polyphenol Content and Total Antioxidant Activity of Vini Novelli (Young Red Wines). J. Agric. Food Chem., v.48, n.3, p.732-7352000.

PIGNATELLI, P.; GHISELLI, A.; BUCHETTI, B.; CARNEVALE, R.; NATELLA, F.; GERMANO, G.; FIMOGNARI, F.; DI SANTO, S.; LENTI, L.; VIOLI, F. Polyphenols synergistically inhibit oxidative stress in subjects given red and white wine. Atherosclerosis, v.188, n.1, p.77-83. Sep 2006.

PIMENTEL, C. V. M. B.; FRANCKI, V. M.; GOLLUCKE, A. P. B. Alimentos funcionais: Introdução às principais substâncias bioativas em alimentosSão Paulo: Ed. Varella, 2005. 
RAJDL, D.; RACEK, J.; TREFIL, L.; SIALA, K. Effect of white wine consumption on oxidative stress markers and homocysteine levels. Physiol Res, v.56, n.2, p.203-122007.

RAMOS, G. R.; ALVES, A. L. H.; HERMES-LIMA, M. Radicais livres, antioxidantes e a adaptabilidade animal. In: R. Dumará (Ed.). O Que é Vida? Para Entender a Biologia do Século XXI. Rio de Janeiro: Relume Dumará, 2000. p.209 - 231

RIZZON, L. A.; MANFROI, L. Sistema de Produção de Vinho Tinto. Embrapa Uva e Vinho - Sistemas de Produção. 122006.

RIZZON, L. A.; MIELE, A. Avaliação da cv. Cabernet Franc para elaboraçao de vinho tinto. Ciência e Tecnologia de Alimentos, v.21, p.249-2552001.

Avaliação da cv. Cabernet Sauvignon para elaboração de vinho tinto. Ciência e Tecnologia de Alimentos, v.22, p.192-1982002.

Avaliação da cv. Merlot para elaboração de vinho tinto. Ciência e Tecnologia de Alimentos, v.23, p.156-1612003.

Avaliação da cv. Tannat para elaboração de vinho tinto. Ciência e Tecnologia de Alimentos, v.24, p.223-2292004.

RIZZON, L. A.; MIELE, A.; MENEGUZZO, J. Avaliação da uva cv. Isabel para a elaboração de vinho tinto. Ciência e Tecnologia de Alimentos, v.20, p.115-1212000.

RIZZON, L. A.; MIELE, A.; MENEGUZZO, J.; ZANUZ, M. C. Efeito de trës processos de vinificação sobre a composição química e a qualidade do vinho Cabernet Franc. Pesq. Agropec. Brasil., v.34, n.7, p.1285-931999.

ROSSETTO, M.; VANZANI, P.; ZENNARO, L.; MATTIVI, F.; VRHOVSEK, U.; SCARPA, M.; RIGO, A. Stable Free Radicals and Peroxyl Radical Trapping Capacity in Red Wines. J. Agric. Food Chem., v.52, n.20, p.6151-61552004.

RUDOLF, E.; ANDELOVA, H.; CERVINKA, M. Polyphenolic compounds in chemoprevention of colon cancer - targets and signaling pathways. Anticancer Agents Med Chem, v.7, n.5, p.559-75. Sep 2007.

SANTOS, J. I. C. Vinhos: O essencial. 5th. São Paulo: Ed. SENAC, 2006.

SAUTTER, C. K.; DENARDIN, S.; ALVES, A. O. M., C.A.;; PENNA, N. G.; HECKTHEUER, L. H. Determinação de resveratrol em sucos de uva no Brasil. Cienc. Tecnol. Aliment., v.25, n.3, p.437-442. jul-set 2005.

SAVASKAN, E.; OLIVIERI, G.; MEIER, F.; SEIFRITZ, E.; WIRZ-JUSTICE, A.; MÜLLER-SPAHN, F. Red Wine Ingredient Resveratrol Protects from b-Amyloid Neurotoxicity. Gerontology, v.49, n.6, p.380-3832003. 
SEERAM, N. P.; AVIRAM, M.; ZHANG, Y.; HENNING, S. M.; FENG, L.; DREHER, M.; HEBER, D. Comparison of antioxidant potency of commonly consumed polyphenolrich beverages in the United States. J Agric Food Chem, v.56, n.4, p.1415-22. Feb 27 2008.

SHAIK, Y. B.; CASTELLANI, M. L.; PERRELLA, A.; CONTI, F.; SALINI, V.; TETE, S.; MADHAPPAN, B.; VECCHIET, J.; DE LUTIIS, M. A.; CARAFFA, A.; CERULLI, G. Role of quercetin (a natural herbal compound) in allergy and inflammation. J Biol Regul Homeost Agents, v.20, n.3-4, p.47-52. Jul-Dec 2006.

SOUSA, C. M. M.; SILVA, H. R.; VIEIRA-JR, G. M.; AYRES, M. C. C.; DA COSTA, C. L. S.; ARAÚJO, D. S.; CAVALCANTE, L. C. D.; BARROS, E. D. S.; ARAÚJO, P. B. M.; BRANDÃO, M. S.; CHAVES, M. H. Fenóis totais e atividade antioxidante de cinco plantas medicinais, 2007.

SUN, B.; SPRANGER, I.; ROQUE-DO-VALE, F.; LEANDRO, C.; BELCHIOR, P. Effect of different winemaking technologies on phenolic composition in Tinta Miuda red wines. J Agric Food Chem, v.49, n.12, p.5809-16. Dec 2001.

VILLAÑO, D.; FERNÁNDEZ-PACHÓN, M. S.; TRONCOSO, A. M.; GARCÍAPARRILLA, M. C. Influence of enological practices on the antioxidant activity of wines. Food Chemistry, v.95, n.3, p.394-4042006.

VITRAC, X.; BORNET, A.; VANDERLINDE, R.; VALLS, J.; RICHARD, T.; DELAUNAY, J. C.; MERILLON, J. M.; TEISSEDRE, P. L. Determination of Stilbenes (\&\#x03B4;-viniferin, trans-astringin, trans-piceid, cis- and trans-resveratrol, \&\#x03B5;viniferin) in Brazilian Wines. J. Agric. Food Chem., v.53, n.14, p.5664-56692005.

WATERHOUSE, A. L. Consumer labels can convey polyphenolic content: implications for public health. Clin Dev Immunol, v.12, n.1, p.43-6. Mar 2005.

WATERHOUSE, A. L.; LAURIE, V. F. Oxidation of Wine Phenolics: A Critical Evaluation and Hypotheses. Am. J. Enol. Vitic., v.3, n.57, p.306-3132006.

Oxidation of Wine Phenolics: A Critical Evaluation and Hypothesis. Am J Enol Vitic, v.57, n.3, p.306-3132006.

WILLIAMS, M. J.; SUTHERLAND, W. H.; WHELAN, A. P.; MCCORMICK, M. P.; DE JONG, S. A. Acute effect of drinking red and white wines on circulating levels of inflammation-sensitive molecules in men with coronary artery disease. Metabolism, v.53, n.3, p.318-23. Mar 2004.

WINE_INSTITUTE. Per capita wine consumption Countries: Wine Institute 2005. 
WOLLIN, S. D.; JONES, P. J. Alcohol, red wine and cardiovascular disease. J Nutr, v.131, n.5, p.1401-4. May 2001.

WU, C. C.; WU, C. I.; WANG, W. Y.; WU, Y. C. Low concentrations of resveratrol potentiate the antiplatelet effect of prostaglandins. Planta Med, v.73, n.5, p.439-43. May 2007.

YILDIRIM, A.; MAVI, A.; KARA, A. A. Determination of Antioxidant and Antimicrobial Activities of Rumex crispus L. Extracts. J. Agric. Food Chem., v.49, n.8, p.4083-40892001.

ZAKHARI, S.; LI, T. K. Determinants of alcohol use and abuse: Impact of quantity and frequency patterns on liver disease. Hepatology, v.46, n.6, p.2032-9. Dec 2007.

ZIMMAN, A.; JOSLIN, W. S.; LYON, M. L.; MEIER, J.; WATERHOUSE, A. L. Maceration variables affecting phenolic composition in Commercial-scale Cabernet Sauvignon Winemaking trials. Am. J. Enol. Vitic., v.53, n.2, p.93-982002. 